\title{
Evolution of Graves's Disease: Impact of Socio-Demographic and Clinical Factors in Senegalese Subject
}

\author{
Djiba Boundia1*, Diedhiou Demba², Sow Djiby², Ndour Michel Assane2, Diallo Ibrahima Mané2, \\ Barrage Ahmed Limane ${ }^{2}$, Ka-Cissé Mariama², Sarr Anna ${ }^{2}$, Ndour-Mbaye Maimouna ${ }^{2}$ \\ ${ }^{1}$ Department of Internal Medicine II, University Hospital Center of Dakar, Cheikh Anta Diop University, Dakar, Senegal \\ ${ }^{2}$ Department of Internal Medicine I, University Hospital Center of Dakar, Cheikh Anta Diop University, Dakar, Senegal \\ Email: ^boundiadjiba@yahoo.fr, dembadiedhiou1976@gmail.com,drdjiby@yahoo.fr, ibrahimamanediallo@hotmail.fr, \\ michelassanendour@yahoo.fr, limaneab@gmail.com, marikacisse@gmail.com,mayoumbaye@gmail.com, annasarr@orange.sn
}

How to cite this paper: Boundia, D. Demba, D., Djiby, S., Assane, N.M., Mané, D.I., Limane, B.A., Mariama, K.-C., Anna, S. and Maimouna, N.-M. (2020) Evolution of Graves's Disease: Impact of Socio-Demographic and Clinical Factors in Senegalese Subject. Open Journal of Internal Medicine, 10, 160-170.

https://doi.org/10.4236/ojim.2020.102017

Received: December 25, 2019

Accepted: May 8, 2020

Published: May 11, 2020

Copyright $\odot 2020$ by author(s) and Scientific Research Publishing Inc. This work is licensed under the Creative Commons Attribution International License (CC BY 4.0).

http://creativecommons.org/licenses/by/4.0/

(c) (i) Open Access

\begin{abstract}
Background: In Graves's disease, there is a lack of description specific to the gender and age among sub-Saharan African subject. The objective was to evaluate the impact of gender and age on the profile of Graves' disease in Senegalese subject in order to understand the evolution and improve the therapeutic choices. Methods: This is a retrospective study conducted from January 1, 2010 to December 31, 2017 (07 years) at Abass Ndao University Hospital (Senegal), focused on patients with Graves' disease followed up under antithyroid drugs treatment for at least 18 months. Results: There were 244 men, 404 subjects between [0 - 25 years], and 101 subjects more than 50 years old. Factors associated with goitre size were male gender $(\mathrm{p}<0.001)$, young age $(\mathrm{p}<0.001)$. Graves orbitopathy was correlated with male gender $(\mathrm{p}$ $=0.015)$, and young age $(\mathrm{p}<0.001)$. Among 580 patients who had stopped medical treatment after more than 18 months of follow-up, relapse involved in $30.3 \%$. Durable remission was achieved in $38.8 \%$ of all included patients and $69.7 \%$ of subjects who had a cessation of medical treatment. The factors associated with sustained remission were female gender $(p=0.049)$, absence of orbitopathy $(p=0.011)$, small goiter $(p<0.001)$, advanced age $(p=0.006)$ and early start of the maintenance treatment $(p=0.006)$. Conclusion: In our Senegalese study, men and young patients are particularized by a trend of voluminous goitre and low rate of remission. These data remain a basis for predicting the outcome of medical treatment and make timely use of radical treatments such as surgery or irratherapy in the presence of risk factors for recurrence.
\end{abstract}




\section{Keywords}

Graves's Disease, Profile, Gender, Age, Senegal

\section{Background}

Graves's disease is an autoimmune disease described by Karl Adolph Von Basedow with a triad associating a vascular diffuse goiter, an acquired exophthalmia, in a young woman with palpitations. The emotional experience seems to precipitate the outbreak of the disease in more than $73 \%$ of cases [1] [2]. It's the most common cause of hyperthyroidism (60\% to $90 \%)$. Young women are the one mainly affected. However, it does not spare men and children and elderly population [1] [2] [3]. It is reported in children and teens in $2 \%$ to $10.7 \%$, elderly in $3.2 \%$ and male subjects in $28.79 \%$ [4] [5] [6]. In Senegal, the first-line treatment choice is based on antithyroid drugs (ATD) [3]. International guidelines recommend an adjustment of the initial dose according to the intensity of hyperthyroidism and the profile of the patient in order to simultaneously obtain antithyroid and immunosuppressive actions without important side effects [7] [8]. The typical patient at risk of failure would be the young smoker with a voluminous goiter, exophthalmos on highly active auto immunity. Smoking represents an independent and powerful factor of relapse [9]. The other therapeutic modalities are ablative surgery and radioactive iodine.

However, despite the frequency and the number of subjects suffering from this disease, the literature's data from the literature are characterized by a lack of description specific to the male, children and elderly subjects. In 2000, Allahabadia et al. [10] had conducted a similar retrospective study of 536 British subjects received for Graves' disease. Gender was not significantly associated with volume of goiter $(p=0.65)$, and frequency of exophthalmos $(p=0.16)$, while male subjects were significantly associated with high intensity of thyrotoxicosis $(\mathrm{p}=0.04)$, and failure of medical treatment $(\mathrm{p}<0.01)$. Young age $(<40$ years $)$ was positively associated with greater goiter $(\mathrm{p}<0.0001)$, frequency of exophthalmos ( $p<0.0001)$, intensity of thyrotoxicosis $(p<0.01)$, and failure of medical treatment $(\mathrm{p}=0.01)$. We have decided, through a comparative study to review the impact of gender and age on the clinical and evolutionary aspects of Graves' disease in Senegalese subjects at the Medical Clinic II of the Abass Ndao Hospital Center of Dakar (Senegal). The practical aspect will be a better understanding of the evolution and improving the therapeutic choices according to the profile of the patient.

\section{Patients and Methods}

The study is carried out at the Medical Clinic II of Abass Ndao University Hospital (Senegal). Any admitted patient for thyroid disease had a follow-up medical file. This was a descriptive and analytic retrospective study conducted from Janu- 
ary 1, 2010 to December 31, 2017. It focused on patients with Graves' disease and followed under antithyroid drugs treatment for at least 18 months at the medical Clinique II. Antithyroid drug therapy employed a titration regimen of Carbimazol or Methimazol, to maintain normal serum free T4 levels. Patient files were used to complete the study data. Clinically and/or biologically incomplete files, patients followed for less than 18 months or for another cause of hyperthyroidism, and patients whose follow-up had started beyond the inclusion period were not considered.

Hyperthyroidism was defined by a low $(<0.1 \mathrm{mIU} / \mathrm{l})$ ultra-sensitive TSH (TSHus) with or without increased thyroid hormones. Graves's disease was an association of hyperthyroidism with one or more of the following signs: acquired orbitopathy, vascular diffuse goiter or myxedema and incidentally a rise of TSH receptor antibody (TRAb). The pre-established form on which the collection was based dealt with the following elements:

- Epidemiological and clinical aspects: The age was divided into three groups ([0 - 25 years], [26 - 50 years] and more than 50 years). The other parameters were gender, family history of thyreopathy and active smoking. The goiter was classified into 4 grades according to the World Health Organization criteria [11]. Graves's orbitopathy was characterized according to the consensus of the European Group on Grave Orbitopathy [12].

- Paraclinical examinations: The plasma values of free tétra-iodothyronine (free T4), free triiodothyronine (free T3) and ultra-sensitive thyrotropine (TSHus) were evaluated at baseline and during the follow-up. The biochemical standards of our laboratory were [0.17 to $4.05 \mathrm{mIU} / \mathrm{l}]$ for ultra-sensitive thyrotropine, [ 9 to $22 \mathrm{pmol} / \mathrm{l}]$ for free T4 and [2.5 to $5.8 \mathrm{pmol} / \mathrm{l}]$ for free T3. Other investigations such as imaging, glycemia, complete blood count, hepatic workup, and electrocardiogram were requested according to the clinical profile. TSH receptor auto antibodies and thyroid scan are not always available in Senegal.

- Medical treatment: We studied the prescribed drugs and their modalities of use. The side effects we were looking for during the first 6 months of treatment were hypothyroidism, agranulocytosis, hepatitis or cholestasis and allergy. We also reviewed the surgical indications. Histological reports were used for the confirmation of Graves' disease. Radioiodine was not yet available in Senegal.

- The evolution: The monitoring of the treatment was clinical and paraclinical (free T4, TSHus) respectively at 1 - 2 months then each 3 months. We assessed the period in establishing maintenance treatment, durable remission, relapse, failure of the medical treatment. The durable remission was defined by a biological stabilization of the disease for at least 12 months after stopping the medical treatment. Relapse occurs after stopping a well-conducted medical treatment regardless of the time. Finally, the failure of the medical treatment was the recurrence of the disease during the maintenance treatment or the lack 
of improvement during treatment for whatever reason, or finally the subjects who presented an evolutionary complication. The evolutionary complications sought were cardiothyreosis, acute thyrotoxic crisis, and moderate to severe orbitopathy [12] [13].

- Data analysis: For the descriptive part, data were presented in percentage for the qualitative variables and as averages for the quantitative variables. For the statistic analysis, the parameters taken into account were group of age ([0 - 25 years], [26 - 50 years] and more than 50 years old), gender, familial dysthyroidism, size of goiter, orbitopathy, intensity of hyperthyroidism, durable remission, relapse. The statistical tests used were the Chi-2 test for qualitative variables and the Student's test for quantitative variables. A p $<0.05$ was considered statistically significant with $95 \%$ of confidence interval (CI). The data entry and exploitation were carried out by the software Epi info version 7.2.2.2.

\section{Results}

\subsection{Epidemiological Aspects}

1040 patients were included, among them 796 women, 244 men, 404 subjects between [0 - 25 years], 535 patients between [26 - 50 years] and 101 subjects more than 50 years old. The average age was 31.5 years. Familial history of dysthyroidism was found in 185 subjects $(17.8 \%)$. The prevalence of familial dysthyroidism increased with young age $(\mathrm{p}=0.005)$. Only 5 patients had an active smoking.

\subsection{Clinical Aspects}

999 patients (96.1\%) had goiter. According to the World Health Organization (WHO) classification [11], goiter was grade 0 to 1 in 214 patients (20.6\%), grade 2 in 540 subjects (51.9\%) and grade 3 in 286 subjects (27.5\%) (See Table 1 ). The large volume of goiter was associated with male gender $(\mathrm{p}<0.001)$, young age ( $\mathrm{p}$ $<0.001)$, grave's orbitopathy $(\mathrm{p}<0.001)$ and family history of dysthyroidism ( $\mathrm{p}$ $=0.005)$.

Grave's orbitopathy was present in 735 patients $(70.7 \%)$. There were $69.7 \%$ of Table 1. Profile and frequency of goiter according to epidemiological parameters.

\begin{tabular}{|c|c|c|c|c|c|}
\hline \multicolumn{2}{|c|}{ Studies parameters } & \multirow{2}{*}{$\begin{array}{c}\text { Goiter } \\
\text { Grade } 0 \text { - } 1\end{array}$} & \multirow{2}{*}{$\begin{array}{c}\text { Goiter } \\
\text { Grade } 2 \\
87(35.6 \%)\end{array}$} & \multirow{2}{*}{$\begin{array}{c}\text { Goiter } \\
\text { Grade } 3 \\
108(42.3 \%)\end{array}$} & \multirow{3}{*}{$\begin{array}{c}\text { p value } \\
0.000\end{array}$} \\
\hline \multirow{2}{*}{ Gender } & $\operatorname{Men}(\mathrm{n}=244)$ & & & & \\
\hline & Female $(\mathrm{n}=796)$ & $165(20.7 \%)$ & $453(56.9 \%)$ & $178(22.4 \%)$ & \\
\hline \multirow{3}{*}{ Age } & {$[0-25$ years $](n=404)$} & $45(11.1 \%)$ & $209(51.7 \%)$ & $150(37.1 \%)$ & \multirow{3}{*}{0.000} \\
\hline & {$[26-50$ years $](n=535)$} & $131(24.5 \%)$ & $282(52.7 \%)$ & $122(22.8 \%)$ & \\
\hline & Over 50 years $(n=101)$ & $38(37.6 \%)$ & $49(48.5 \%)$ & $14(13.9 \%)$ & \\
\hline \multirow{2}{*}{ Orbitopathy } & Yes $(n=735)$ & $137(18.6 \%)$ & $383(52.1 \%)$ & $215(29.3 \%)$ & \multirow{2}{*}{0.000} \\
\hline & No $(n=305)$ & $77(25.2 \%)$ & $157(51.5 \%)$ & $71(23.3 \%)$ & \\
\hline
\end{tabular}


men, $71 \%$ of women, and $79.0 \%$ of subjects in the range [ 0 - 25 years old], $67.0 \%$ of subjects in the range [ 26 - 50 years] and $56.4 \%$ of subjects over 50 years old. According to the consensus of the European Group on Grave's Orbitopathy [12], orbitopathy was moderate to severe in $0.8 \%$ of cases. The orbitopathy was most frequent in male gender $(\mathrm{p}=0.015)$, young age $(\mathrm{p}<0.001)$ and when the goiter is bigger $(\mathrm{p}<0.001)$.

The average free T4 was $68.5 \mathrm{pmol} / \mathrm{l}$ and free T4 was $>50 \mathrm{pmol} / \mathrm{l}$ in $67.2 \%$ of cases. This percentage was made of $70.7 \%$ of men, $66.1 \%$ of women, $70.6 \%$ of subjects between [0 - 25 years], $67.7 \%$ of those between [ $26-50$ years] and $63.9 \%$ of the population over 50 years old. Depending on the volume of the goiter, it was $54.1 \%$ of grade $0-1$ goiter, $70 \%$ grade 2 , and $77.3 \%$ grade 3 . The intensity of hyperthyroidism was only correlated with goiter size $(\mathrm{p}<0.001)$ and young age $(\mathrm{p}=0.038)$.

The progressive complications were 8 cases of moderate to severe orbitopathy, 3 cases of acute thyrotoxic crisis and 75 cases of cardiothyrosis. Severe orbitopathy was associated with male gender $(\mathrm{p}=0.018)$, cardiothyrosis with older age ( $\mathrm{p}$ $=0.005)$ and goiter size $(p=0.001)$. No correlation was found for the acute thyrotoxic crisis.

\subsection{Therapeutic Aspects}

All patients had initially received medical treatment with antithyroid drugs (such as methimazole or carbimazol). The average daily dose of the initial treatment was $37.4 \mathrm{mg}$. According to the profile of subjects, it was $37.3 \mathrm{mg} / \mathrm{d}$ in women, 37.6 $\mathrm{mg} / \mathrm{d}$ in men, $36.2 \mathrm{mg} / \mathrm{d}$ in subjects between [0 - 25 years], $38.4 \mathrm{mg} / \mathrm{d}$ in subjects aged [ 26 - 50 years] and $37.2 \mathrm{mg} / \mathrm{d}$ in subjects more than 50 years old.

The adverse effects found in the first 6 months of treatment were mainly hypothyroidism under treatment in 152 subjects (14.6\%) at 3 months and 207 cases (19.9\%) at 6 months of follow-up (See Table 2). Other side effects were agranulocytosis in 10 subjects $(0.4 \%)$, transient allergic reaction in 231 subjects $(10.3 \%)$, and hepatitis in 30 subjects (1.3\%).

At 3 months of follow-up, a therapeutic maintenance dose of antithyroid drugs was introduced for more than 9 months in only 314 patients (30.2\%). Factors most associated with the early onset of maintenance therapy were small goitre volume $(p=0.016)$ and absence of orbitopathy $(p=0.001)$. We did not find significant correlation with age and gender $(\mathrm{p}>0.05)$. The frequency of hypothyroidism and the time in putting on maintenance treatment are shown in Table 2.

\subsection{Evolutionary Aspects}

Failure of medical treatment was found in 460 cases (44.2\%). Among them, only 274 patients (59.6\%) were able to benefit from a thyroidectomy. The others had chosen the long-term medical treatment option. We report that irratherapy is not currently available in Senegal. Weaning from medical treatment was found in 580 cases (55.8\%). Among them, the relapse after antithyroid drugs withdrawal 
involved 176 cases (30.3\%). A durable remission was achieved in 404 patients. That is $38.8 \%$ of all included patients and $69.7 \%$ of them who received an authorized discontinuation of medical treatment. The factors associated with sustained remission were female gender $(\mathrm{p}=0.049)$, absence of orbitopathy $(\mathrm{p}=$ $0.011)$, small size of goiter $(\mathrm{p}<0.001)$, advanced age $(\mathrm{p}=0.006)$ and the early delay to start the maintenance treatment $(\mathrm{p}=0.006)$ (See Table 3$)$.

\section{Discussion}

We corroborate the existence of a clinical and evolutionary feature of the Grave's

Table 2. Profile of iatrogenic hypothyroidism and therapeutic maintenance dose of ATS.

\begin{tabular}{clcc}
\hline \multicolumn{2}{c}{ Studies parameters } & $\begin{array}{r}\text { Hypothyroidism } \\
\text { under treatment }\end{array}$ & $\begin{array}{c}\text { Maintenance dose of ATD } \\
\text { between 3 and 9 months }\end{array}$ \\
\hline Gender & Female $(\mathrm{n}=796)$ & $113(14.2 \%)$ & $241(30.3 \%)$ \\
Mge & {$[0-25$ years $](\mathrm{n}=404)$} & $59(16 \%)$ & $73(29.9 \%)$ \\
& {$[26-50$ years $](\mathrm{n}=535)$} & $75(14 \%)$ & $109(27 \%)$ \\
Orbitopathy & Yes $(\mathrm{n}=735)$ & $18(17.8 \%)$ & $43(42.6 \%)$ \\
& No $(\mathrm{n}=305)$ & $106(14.4 \%)$ & $208(28.3 \%)$ \\
& Grade $0-1(\mathrm{n}=214)$ & $46(15 \%)$ & $106(34.8 \%)$ \\
Size of goiter & Grade $2(\mathrm{n}=540)$ & $38(17.7 \%)$ & $160(29.6 \%)$ \\
& Grade 3 $(\mathrm{n}=286)$ & $82(15.1 \%)$ & $72(25.29 \%)$
\end{tabular}

Table 3. Evolutionary profile of the subjects.

\begin{tabular}{|c|c|c|c|}
\hline \multicolumn{2}{|c|}{ Studies parameters } & \multirow{2}{*}{$\begin{array}{c}\text { Sustainable remission } \\
321(40.3 \%)\end{array}$} & \multirow{2}{*}{$\begin{array}{c}\text { p value } \\
0.049\end{array}$} \\
\hline Gender & Female $(\mathrm{n}=796)$ & & \\
\hline \multirow{4}{*}{ Age } & Male $(\mathrm{n}=244)$ & $83(34 \%)$ & \\
\hline & {$[0-25$ years $](n=404)$} & $146(36.1 \%)$ & 0.006 \\
\hline & {$[26-50$ years $](n=535)$} & $207(38.7 \%)$ & \\
\hline & Over 50 years $(\mathrm{n}=101)$ & $51(50.5 \%)$ & \\
\hline \multirow[t]{2}{*}{ Orbitopathy } & Yes $(n=735)$ & $270(36.7 \%)$ & 0.011 \\
\hline & No $(n=305)$ & $134(43.9 \%)$ & \\
\hline \multirow[t]{3}{*}{ Size of goiter } & Grade $0-1(n=214)$ & $108(50.5 \%)$ & 0.000 \\
\hline & Grade $2(n=540)$ & $210(38.9 \%)$ & \\
\hline & Grade $3(n=286)$ & $86(30.1 \%)$ & \\
\hline \multirow{2}{*}{$\begin{array}{l}\text { Initial dose of antithyroid } \\
\text { drugs (ATD) }\end{array}$} & $\geq 40 \mathrm{mg} / \mathrm{d}(\mathrm{n}=648)$ & 277 (42.7\%) & 0.183 \\
\hline & $<40 \mathrm{mg} / \mathrm{d}(\mathrm{n}=392)$ & $157(40.1 \%)$ & \\
\hline \multirow{2}{*}{$\begin{array}{l}\text { Delay to start the } \\
\text { maintenance treatment of ATD }\end{array}$} & $\leq 3$ months $(\mathrm{n}=314)$ & $148(47.1 \%)$ & 0.006 \\
\hline & $\geq 6$ months $(n=726)$ & $256(35.3 \%)$ & \\
\hline
\end{tabular}


disease according to the age and gender in Senegalese subjects. In our study, male subject is particularized by a greater frequency of the orbitopathy, a high fréquence of voluminous goitre and a low rate of remission. In the young patient, it is the high frequency of familial dysthyroidism, a tendency to bulky goiter and a high rate of therapeutic failure that prevails. These data were obtained with a significant statistic correlation.

\subsection{Epidemiological Aspects}

The female predominance in Grave's disease is known. The poorly described profile is the male particularities with frequencies ranging from $12.1 \%$ to $17.2 \%$ in the West [10] [13] and $8.6 \%$ to $28.7 \%$ in Africa [3] [5] [14]. The inclusion of children and teenagers in our study explains the decline in the average age at 31.1 years. However, no age difference could be reported by sex [3] [7]. The importance of environment and genetics in the genesis of Graves' disease is known [15] [16] [17]. According to Manji et al. [18], the existence of familial history of thyreopathy was associated with the male subject $(\mathrm{p}=0.004)$. In our series, it increased rather with the young age. In the specific case of the male population, Manji et al. [18] and Allahabadia et al. [10] reported a history of familial thyropathy in (40\% and $42.5 \%)$ and smoking in (31.4\% and $44 \%)$ respectively.

\subsection{Clinical Aspects}

The frequency of the specific signs of Graves' disease was identical to the literature data [3] [7] [14] [19]. Sarr et al. [3] in Senegal reported an orbitopathy (65.9\%) and goiter (97.3\% of which $75.3 \%$ grade 2 and 3$)$. Goitre appears to be more common in women, but male subject is characterized by larger goiters and a higher frequency of orbitopathy [10] [18] [20]. Literature data report a large goiter and exophthalmia positively correlated with young age [10] [15] [18] [20] [21]. In the series of Diédhiou et al. [5] in male subjects, orbitopathy was statistically correlated with the large size of goiter $(p=0.0001)$.

In our series, apart from the young age $(\mathrm{p}<0.05)$, gender and the patient's environment did not seem to influence the intensity of thyrotoxicosis. Manji et al. [18] from an English cohort of 2405 Grave's diseases, reported that the presence of goiter was independently associated with the severity of the disease at diagnosis $(\mathrm{p}<0.001)$. In addition, free $\mathrm{T} 4(\mathrm{p}<0.05)$ and active smoking $(\mathrm{p}<$ 0.001 ) were two others independent predictors of Grave's orbitopathy.

In sub-Saharan Africa, therapeutic disruption and delayed management explain in part the high rate of complications mainly cardiovascular [22]. The typical profile at risk of acute thyrotoxic crisis is the young woman with an orbitopathy. The male subject with goiter and smoking is at risk of moderate to severe orbitopathy [12] [23]. As for cardiothyrosis, it seems more to be the prerogative of the elderly with goitre. It was reported at $9.8 \%$ and $16.6 \%$ respectively in Senegal [24] and Morocco [25]. Among the risk factors for cardiothyrosis, Diedhiou et al. [24] reported that female gender were at risk of rhythm disturbance $(\mathrm{p}=$ 
$0.01)$ and right ventricular dysfunction $(\mathrm{p}=0.007)$ and the intensity of thyrotoxicosis at risk of pulmonary arterial hypertension $(\mathrm{p}=0.05)$.

\subsection{Therapeutic and Evolutionary Aspects}

Medical treatment remains the preference in Europe, Latin America and Japan [7]. In our series, the factors most associated with early maintenance therapy were the small volume of goiter and advanced age. In case of persistent hyperthyroidism, the surgical indication should be considered. However, the option of low-dose prolonged medical treatment may be selected based on the patient's preference [7] [26]. In the absence of irratherapy not available in Senegal, many of our patients preferred the long-term medical option despite its inefficiency.

The sustainable remission rate varies considerably by geographic area. We report a sustained remission of $38.8 \%$ according to the initial population. In the US, remission rates from $20 \%$ to $30 \%$ were reported after 12 to 18 months of medical treatment [27]. A European study of 5 to 6 years of medical treatment with ATS reports a remission in $50 \%$ to $60 \%$. Two metaanalysis [28] [29] reported a high rate of relapse in $49 \%$ to $52.7 \%$. According to the meta-analysis evaluating 54 trials and 7595 participants, the main risk factors for relapse [30] were orbitopathy, smoking, thyroid volume, intensity of thyrotoxicosis, and TSH-R-Ab value.

Like our study, male gender and children are more likely to relapse, especially if he is smoking or has a large goiter [9] [10] [25] [30]. According to a study in the male subject, the failure of medical treatment was significantly correlated with young age $[\mathrm{OR}=1.96(1.11-3.47), \mathrm{p}=0.009]$, the size of goiter $[\mathrm{OR}=2.50$ (1.34 - 4.64), $\mathrm{p}=0.002$ ] and intensity of hyperthyroidism [OR $=1.89$ (1.04 4.22), $\mathrm{p}=0.017$ ] [5]. Finally, in children, Kaguelidou et al. [31] reported that the overall estimated relapse rate for hyperthyroidism was $59 \%$ at 1 year and $68 \%$ at 2 years after the end of treatment. In multivariate analysis, the risk of relapse was higher for patients of non Caucasian origin [HR $=2.54, \mathrm{p}<0.001$, with high serum thyroid-stimulating hormone receptor antibodies $(\mathrm{HR}=1.21, \mathrm{p}<0.03)$ and free T4 $(\mathrm{HR}=1.18$ by $10 \mathrm{pmol} / \mathrm{l}, \mathrm{p}<0.001)$ levels at diagnosis. Conversely, relapse risk decreased with increasing age at onset $(\mathrm{HR}=0.74$ per 5 years, $\mathrm{p}<$ 0.03 ) and duration of first course of ATD ( $\mathrm{HR}=0.57$ per 12 months, $\mathrm{p}<0.005)$. In a prospective study introducing the quantitative predictive "GREAT" score for Graves's disease, 37\% of patients with a first episode of Graves' hyperthyroidism relapsed within 2 years after antithyroid drugs withdrawal. Lower age, higher serum TSH-Receptor antibody and free T4, larger goiters at diagnosis were independent predictors for recurrence [32].

\section{Conclusion}

We corroborate the existence of a clinical and evolutionary feature of the Grave's disease according to the age and gender in Senegalese subjects. In our study, male subject is particularized by a greater frequency of the orbitopathy, a high 
frequence of voluminous goitre and a low rate of remission. In the young patient, it is the high frequency of familial dysthyroidism, a tendency to bulky goiter and a high rate of therapeutic failure that prevails. Apart from environmental factors (stress, smoking, therapeutic accessibility), the large volume of goitre remains a determining factor of failure or recurrence after a well-conducted medical treatment. These data remain a basis for predicting the outcome of medical treatment and making timely use of radical treatments such as surgery or irratherapy in the presence of risk factors for recurrence. A prospective study using the same therapeutic modalities and monitoring of the TSH receptor auto antibodies would be highly suitable.

\section{Limitation of the Study}

The study weaknesses were mainly due to the fact that it was an observational study, that some files were incomplete for reasons of accessibility, and lastly, the difficulties of long-term follow-up.

\section{Contributions of Authors}

Djiba Boundia: Conception and writing of the manuscript; Demba Diédhiou, Sow Djiby, Ndour Michel Assane, Ahmed Limane Dam, Ibrahima Mané Diallo, Anna Sarr, and Ndour Mbaye Maimouna: corrections, suggestions and approval of the final version of the manuscript.

\section{Thanks}

To all who contributed to the development of this work.

\section{Conflicts of Interest}

The authors do not declare any conflict of interest.

\section{References}

[1] Wémeau, J.L., et al. (2006) Hyperthyroidism: Encycl Méd. Chir. EndocrinologieNutrition. Paris, France, 17.

[2] Diop, S.N., Diédhiou, D., Sarr, A., et al. (2011) Psychological Aspects and Psychiatric Manifestation of Grave's Disease about 104 Cases. Revue du CAMES, 12, 62-64.

[3] Sarr, A., Diédhiou, D., Ndour-Mbaye, N.M., et al. (2016) Graves' Disease in Senegal: Clinical and Evolutionary Aspects. Open Journal of Internal Medicine, 6, 77-82. https://doi.org/10.4236/ojim.2016.63013

[4] Ka-Cissé, M., Diop, S.N., Ndour, M., Sarr, A., Sidibé, E.H. and Sow, A.M. (1999) Graves' Disease in Children and Adolescents in Senegal. La Revue francaise dendocrinologie clinique, nutrition, et metabolisme, 40, 99-106.

[5] Diédhiou, D., Diallo, I.M., Ndour, M.A., et al. (2018) Graves' Disease in Men's Subjects. Journal of Human Endocrinology, 3, 12. https://doi.org/10.24966/HE-9640/100012

[6] Abraham-Nordling, M., Bystrom, K., Torring, O., et al. (2011) Incidence of Hyperthyroidism in Sweden. European Journal of Endocrinology, 165, 899-905. 
https://doi.org/10.1089/thy.2016.0229

[7] Ross, D.S., Burch, H.B., Cooper, D.S., et al. (2016) American Thyroid Association Guidelines for Diagnosis and Management of Hyperthyroidism and Other Causes of Thyrotoxicosis. Thyroid, 26, 1343-1421. https://doi.org/10.1089/thy.2016.0229

[8] Wartofsky, L., Glinoer, D., Solomon, B., et al. (1991) Differences and Similarities in the Diagnosis and Treatment of Graves' Disease in Europe, Japan, and the United States. Thyroid, 1, 129-135. https://doi.org/10.1089/thy.1991.1.129

[9] Kimball, L.E., Kulinskaya, E., Brown, B., Johnston, C. and Farid, N.R. (2002) Does Smoking Increase Relapse Rates in Graves' Disease? Journal of Endocrinological Investigation, 25, 152-157. https://doi.org/10.1007/BF03343979

[10] Allahabadia, A., Daykin, J., Holder, R.L., Sheppard, M.C., Gough, S.C.L. and Franklyn, J.A. (2000) Age and Gender Predict the Outcome of Treatment for Graves' Hyperthyroidism. The Journal of Clinical Endocrinology \& Metabolism, 85, 1038-1042. https://doi.org/10.1210/jc.85.3.1038

[11] Perez, C., Scrimshaw, N.S. and Munoz, J.A. (1960) Technique of Endemic Goitre Surveys. Monograph Series. World Health Organization, 44, 369-383.

[12] Bartalena, L., Baldeschi, L., Dickinson, A.J., et al. (2008) Consensus Statement of the European Group on Graves' Orbitopathy (EUGOGO) on Management of GO. European Journal of Endocrinology, 158, 273-285. https://doi.org/10.1530/EJE-07-0666

[13] Goichot, B., Caron, P., Landron, F. and Bou, S. (2016) Clinical Presentation of Hyperthyroidism in a Large Representative Sample of Outpatients in France: Relationships with Age, Etiology and Hormonal Parameters. Clinical Endocrinology, 84, 445-451. https://doi.org/10.1111/cen.12816

[14] Diagne, N., Faye, A., Ndao, A.C., et al. (2016) Epidemiological, Clinical, Therapeutic and Evolutive Aspects of Graves's Disease in the Department of Internal Medicine at CHU Aristide Le Dantec, Dakar (Senegal). Pan African Medical Journal, 25, 6. https://doi.org/10.11604/pamj.2016.25.6.7868

[15] Boiro, D., Diédhiou, D., Niang, B., et al. (2017) Hyperthyroidism in Children at the University Hospital in Dakar (Senegal). Pan African Medical Journal, 28, 10. https://doi.org/10.11604/pamj.2017.28.10.13396

[16] Léger, J. and Carel, J.C. (2013) Hyperthyroidism in Childhood: Causes, When and How to Treat. Journal of Clinical Research in Pediatric Endocrinology, 5, 50-56.

[17] Deleveaux, I., Chamoux, A. and Aumaître, O. (2013) Stress and Auto-Immunity. La Revue de Médecine Interne, 34, 487-492.

https://doi.org/10.1016/j.revmed.2012.10.366

[18] Manji, N., Carr-Smith, J.D., Boelaert, K., et al. (2006) Influences of Age, Gender, Smoking, and Family History on Autoimmune Thyroid Disease Phenotype. The Journal of Clinical Endocrinology \& Metabolism, 91, 4873-4880. https://doi.org/10.1210/jc.2006-1402

[19] Hadj Ali, I., Khiari, K., Chérif, L., et al. (2004) Treatment of Graves' Disease: 300 Cases. La Presse Médicale, 33, 17-21. https://doi.org/10.1016/S0755-4982(04)98466-7

[20] Magri, F., Zerbini, F., Gaiti, M., et al. (2016) Gender Influences the Clinical Presentation and Long-Term Outcome of Graves Disease. Endocrine Practice, 22, 1336-1342. https://doi.org/10.4158/EP161350.OR

[21] Leger, J., Kaguelidou, F., Alberti, C. and Carel, J.C. (2014) Graves' Disease in Children. Best Practice \& Research Clinical Endocrinology \& Metabolism, 28, 233-243. 
https://doi.org/10.1016/j.beem.2013.08.008

[22] Akossou, S.Y., Napporn, A., Oeh-Akuee, G., et al. (2001) Problems in the Management of Thyrotoxicosis in Black Africa: The Tongolese Experience. Annales d Endocrinologie, 62, 516-520.

[23] Wong, K.P. and Lang, B.H. (2011) Graves' Ophthalmopathy as an Indication Increased the Risk of Hypoparathyroidism after Bilateral Thyroidectomy. World Journal of Surgery, 35, 2212-2218. https://doi.org/10.1007/s00268-011-1236-y

[24] Diédhiou, D., Sow, D., Lèye, M.M., et al. (2017) Cardiothyreosis: Risk Factors and Clinical Profile. Open Journal of Internal Medicine, 7, 1-11. https://doi.org/10.4236/ojim.2017.71001

[25] Bouziane, T., Larwanou, M. and El Ouahabi, H. (2017) The Predictive Factors of Relapse in Graves Disease Treated by ATS: About 72 Cases. Annales d Endocrinologie, 78, 326-352. https://doi.org/10.1016/j.ando.2017.07.370

[26] Kahalya, G.J., Bartalenab, L., Hegedüsc, L., Leenhardtd, L., Poppee, K. and Pearcef, S.H. (2018) 2018 European Thyroid Association Guideline for the Management of Graves' Hyperthyroidism. European Thyroid Journal, 7, 167-186. https://doi.org/10.1159/000490384

[27] Klein, I., Becker, D.V. and Levey, G.S. (1994) Treatment of Hyperthyroid Disease. Annals of Internal Medicine, 121, 281-288. https://doi.org/10.7326/0003-4819-121-4-199408150-00010

[28] Sundaresh, V., Brito, J.P., Wang, Z., et al. (2013) Comparative Effectiveness of Therapies for Graves' Hyperthyroidism: A Systematic Review and Network Meta-Analysis. The Journal of Clinical Endocrinology \& Metabolism, 98, 3671-3677. https://doi.org/10.1210/jc.2013-1954

[29] Struja, T., Fehlberg, H., Kutz, A., et al. (2017) Can We Predict Relapse in Graves' Disease? Results from a Systematic Review and Meta-Analysis. European Journal of Endocrinology, 176, 87-97. https://doi.org/10.1530/EJE-16-0725

[30] Léger, J. and Carel, J.C. (2017) Magement of Endocrine Disease/Arguments for the Prolonged Use of Antithyroid Drugs in Children with Graves' Disease. European Journal of Endocrinology, 177, 59-67. https://doi.org/10.1530/EJE-16-0938

[31] Kaguelidou, F., Alberti, C., Castanet, M., Guitteny, M.A., Czernichow, P. and Leger, J. (2008) Predictors of Autoimmune Hyperthyroidism Relapse in Children after Discontinuation of Antithyroid Drug Treatment. The Journal of Clinical Endocrinology \& Metabolism, 93, 3817-3826. https://doi.org/10.1210/jc.2008-0842

[32] Vos, X.G., Endert, E., Zwinderman, A.H., Tijssen, J.G. and Wiersinga, W.M. (2016) Predicting the Risk of Recurrence before the Start of Antithyroid Drug Therapy in Patients with Graves' Hyperthyroidism. The Journal of Clinical Endocrinology \& Metabolism, 101, 1381-1389. https://doi.org/10.1210/jc.2015-3644 